\section{Sustainability of family medicine}

C anada is experiencing a shortage of family physicians. Bruce Wright and associates ${ }^{1}$ have identified several factors that might be used to increase the number of medical students choosing to enter family medicine. For its part, the Professional Association of Internes and Residents of Ontario recently developed a position paper on the sustainability of family medicine, offering a view of this crisis from the perspective of Ontario's new physicians. ${ }^{2}$

As our position paper states, ${ }^{1}$ we believe that the lack of interest in family medicine initially develops during training, for a variety of reasons, including a lack of exposure to effective teamwork between family physicians and specialists. In addition, the position paper identifies many societal factors that have influenced the decline in supply of family physicians in Canada. All of these factors will require short-term interventions married with a long-term strategy.

Positive exposure to family practice in medical school and clerkship can spark new interest in the field, as well as reinforcing existing interest. For such exposure to occur, a cadre of dynamic and enthusiastic family physicians is required both within medical schools and in community practice. The concerns of practising family physicians, including reasonable workloads and appropriate payment mechanisms, must be addressed to make such student experiences possible, and new family physicians must be encouraged to undertake a mentorship role and must be supported in fulfilling that role.

\section{Alex McPherson}

Psychiatry (PGY4)

University of Toronto

Toronto, Ont.

\section{References}

1. Wright B, Scott I, Woloschuk W, Brenneis F. Career choice of new medical students at three Canadian universities: family medicine versus specialty medicine. CMA7 2004;170(13):1920-4.

2. Primary importance: new physicians and the future of family medicine. Position paper on the sustainability of family medicine. [place unknown]: Professional Association of Internes and Residents of Ontario; 2004. Available: www.pairo .org/Content/Files/Primary\%20Importance.pdf (accessed 2004 Aug 23).

DOI:10.1503/cmaj.1041157

\section{Right reaction, wrong response}

Twas disturbed by Lucie Opatrny's 1 description ${ }^{1}$ of viewing a secondtrimester termination when she was a 15 -year-old high school student. This encounter was unethical from the patient's perspective; furthermore, it was inappropriate for a high school student to witness such a procedure - no wonder she fainted!

Opatrny also describes her recent reaction as a practising physician to viewing what was clearly an incident of child abuse. She "reproached" the mother, then vomited. Why did she not call child protection services, as she is required to do by law? Did her visceral reaction not indicate how abhorrent the behaviour she had witnessed was? In both situations, her "uncontrollable visceral responses" were appropriate, not idiosyncratic. Opatrny should learn to listen to her body.

\section{Barbara A. Bulleid}

Dr. Everett Chalmers Hospital

Fredericton, NB

\section{Reference \\ 1. Opatrny L. Achilles' heel. CMAf 2004;171(8): 910.}

DOI:10.1503/cmaj.1041704

\section{[The author responds:]}

r. Bulleid may be placated to know that this case was abbreviated to preserve patient confidentiality, and that the child protection authorities were involved appropriately. However, physician responsibility to contact Child Protection Services in cases of suspected child abuse is always a worthwhile reminder. As for my reactions, I do not claim they were anything but appropriate extreme reactions, in response to extreme situations.

\section{Lucie Opatrny \\ McGill University \\ Montréal, Que.}

DOI:10.1503/cmaj.1041705

\section{Neural tube defects}

The primary finding reported by 1 Joel Ray and associates ${ }^{1}$ in their study of ethnicity in relation to the development of neural tube defects that babies born to First Nations women have a higher risk of neural tube defects - should be interpreted with caution.

The calculation of the relative risk of a neural tube defect for a child with a First Nations mother is based on 5 cases occurring among 1551 subjects. The ethnicity category for "other" (which included Hispanic women) had 1 case among 10009 subjects. The protective effect observed in this group was not mentioned in the study's interpretation, despite the broader base of subjects.

Such small numbers may cause several problems. One is that a few misclassifications of the First Nations cases could create the appearance of an effect where none actually exists. Also, given that multiple categories were examined, the authors should have considered some form of adjustment for multiple comparisons. ${ }^{2}$

In general, one should be careful not to overinterpret results obtained in small subpopulations. While the hypothesis suggested by Ray and associ- 
ates is intriguing, we should gather more evidence before changing policy.

\section{J.A. Chris Delaney \\ Statistician \\ Royal Victoria Hospital \\ Montréal, Que. \\ References \\ 1. Ray JG, Vermeulen MJ, Meier C, Cole DEC Wyatt PR. Maternal ethnicity and risk of neura tube defects: a population-based study. CMAf 2004:171(4):343-5. \\ 2. Aickin M, Gensler H. Adjusting for multiple testing when reporting research results: the Bon- ferroni vs Holm methods. Am 7 Public Health 1996;86(5):726-8.}

DOI:10.1503/cmaj.1041540

A lthough Joel Ray and associates ${ }^{1}$ may have adequately controlled for confounding in their study of neural tube defects among children born in Ontario, the study may suffer from bias in data collection, analysis and interpretation, and the conclusions drawn may therefore be premature.

The study included Ontario women who underwent antenatal maternal serum screening at 15 to 20 weeks' gestation over the period 1994 to 2000, with an uptake rate of about $70 \% .{ }^{1}$ The proportion of First Nations women in the study $(1551 / 403915,0.38 \%)$ was much lower than the proportion of First Nations women in Ontario, as estimated by the 2001 Census ( 92050 or $1.9 \%$ of the total female population). ${ }^{2}$ Because First Nations women tend to have a higher fertility rate, the true proportion of pregnant women of First Nations origin in Ontario is likely at least 5 times the proportion reported in the study. As reported by others ${ }^{3}$ and in our previous analysis,${ }^{4}$ First Nations women are less likely to access prenatal care and more likely to access it at a later stage of pregnancy than women in the general population. Therefore, Ray and associates probably missed a large number of First Nations women in Ontario who did not access maternal serum screening before 20 weeks' gestation. Failure to include all pregnant First Nations women in this study, particularly in the denominator for a risk calculation, could lead to overestima- tion of the risk for neural tube defects among pregnant First Nations women in Ontario.

Using population-based registry data from the Alberta Congenital Anomalies Surveillance System combined with data from the Alberta Health Care Insurance Plan, which captures nearly all First Nations persons in Alberta with treaty status under the Indian Act of Canada, we examined the live-birth prevalence of congenital anomalies in 268167 newborns, including 16986 First Nations children, from 1995 to $2001 . .^{5}$ We found 4 cases of neural tube defects, a rate of 0.24 per 1000 First Nations newborns (95\% confidence interval [CI] 0.01-0.47). This result was similar to the rate for other Alberta newborns ( 0.33 per 1000 , 95\% CI 0.25-0.40). Thus, we did not witness a greater risk of neural tube defects for First Nations newborns. Our finding is consistent with that of an earlier report with a much larger sample size in British Columbia. ${ }^{6}$

Our data show that pregnancy terminations and stillbirths account for about $50 \%$ of all cases of neural tube defects registered in Alberta between 1997 and 2001. However, data on ethnicity are currently unavailable for cases of termination and stillbirth. Future collection of such data will allow a better estimation of the risk for neural tube defects among First Nations people and people of other ethnic origins.

\section{Fu-Lin Wang}

Epidemiologist

Health Surveillance

Alberta Health and Wellness

Edmonton, Alta.

Hude Quan

Assistant Professor

University of Calgary

Calgary, Alta.

Donald Schopflocher

Senior Biostatistician

Health Surveillance

Alberta Health and Wellness

Edmonton, Alta.

\section{References}

1. Ray JG, Vermeulen MJ, Meier C, Cole DEC, Wyatt PR. Maternal ethnicity and risk of neural tube defects: a population-based study. CMAJ
2004;171(4):343-5.

2. Ethnic origin, sex and single and multiple responses for population, for Canada, provinces, territories, census metropolitan areas and agglomerations, 2001 Census - $20 \%$ sample data. Ottawa: Statistics Canada; 2003 Jan 21. Cat no. 97F0010XCB01001.

3. Plunkett A, Lancaster P, Huang J; National Perinatal Statistics Unit (Australia). Indigenous mothers and their babies, Australia 1991-1993. Sydney: Australian Institute of Health and Welfare, National Perinatal Statistics Unit; 1996.

4. Wang FL, Larke B, Hanrahan A, Guyon G, Findlay L, Gabos S. Non-acceptance to HIV testing in a routine prenatal HIV screening program [poster]. International Epidemiological Association; 16th World Congress of Epidemiology; 2002 Aug 18-22; Montréal.

5. Wang FL, Lowry RB, Quan H, Sibbald BS, Nguyen TH, Schopflocher D, et al. Birth prevalence of congenital anomalies in Chinese, First Nations, Vietnamese, and Hutterites newborns, Alberta, 1995-2001 [oral presentation]. 2nd scientific meeting of Canadian Congenital Anomalies Surveillance Network; 2003 Oct 19-21; Edmonton

6. Lowry RB, Thunem NY, Silver M. Congenital anomalies in American Indians of British Columbia. Genet Epidemiol 1986;3:455-67.

\section{DOI:10.1503/cmaj.1041688}

$\mathrm{T}$ he population-based study of neural tube defects by Joel Ray and associates ${ }^{1}$ raises 2 important concerns. First, as noted by the authors in their discussion of study limitations, ethnicity may simply be a confounding factor in neural tube defects caused by poor folic acid intake. Second, perhaps the maternal serum screening form should be used to obtain additional information on risk factors for neural tube defects, to allow researchers to study this rare public health issue. Even a crude measure of folic acid intake (e.g., as low, medium or high) would be more helpful than no information at all.

\section{Vinita Dubey}

Resident in Community Medicine

University of Toronto

Toronto, Ont.

\section{Reference}

1. Ray JG, Vermeulen MJ, Meier C, Cole DEC, Wyatt PR. Maternal ethnicity and risk of neural tube defects: a population-based study. CMAJ 2004;171(4):343-5.

\section{DOI:10.1503/cmaj.1041603}

Toel Ray and associates ${ }^{1}$ found that in Ontario the risk of neural tube defects was higher among First Nations 